\title{
EFEITOS DAS FONTES E NÍVEIS DE LIPÍDIOS NAS DIETAS DE RATOS MACHOS DA LINHAGEM WISTAR (Rattus norvegicus) SOBRE FRAÇÕES LIPÍDICAS DO SANGUE ${ }^{1}$
}

\author{
CECÍLIA SANDRA NUNES MORAIS ${ }^{2}$ \\ MARIA DE FÁTIMA PÍCCOLO BARCELOS ${ }^{3}$ \\ RAIMUNDO VICENTE DE SOUSA ${ }^{3}$ \\ HESSEL MARANI LIMA ${ }^{4}$ \\ ANDRELISA LINA DE LIMA ${ }^{5}$
}

\begin{abstract}
RESUMO - Foram estudadas quatro fontes lipídicas (óleo de soja, óleo de canola, azeite de oliva e gordura suína) em dois níveis na dieta (7 e 14\%), verificando a influência do consumo dessas fontes lipídicas sobre algumas frações lipídicas do sangue de ratos. Assim, oito grupos de ratos machos da linhagem Wistar (Rattus norvegicus) foram alimentados ad libitum por 56 dias com oito dietas distintas contendo as fontes e níveis citados de lipídios. As dosagens de colesterol total e triacilgliceróis no soro foram realizadas pelo método colo-
\end{abstract}

rimétrico/enzimático utilizando "kit" comercial específico. O colesterol em HDL foi determinado por precipitação dos quilomícrons, VLDL e LDL, utilizando também "kit" específico. O aumento de lipídios na dieta para $14 \%$ elevou os valores de colesterol total, HDLcolesterol e LDL+VLDL-colesterol séricos, quando a fonte foi a gordura suína. Com $14 \%$ de lipídios na dieta, os menores valores de triacilgliceróis séricos foram observados nas fontes lipídicas óleo de soja e canola, com valores de 76,09 e 84,42 mg/dL, respectivamente.

TERMOS PARA INDEXAÇÃO: Fontes lipídicas, análises sangue, colesterol, triacilgliceróis, ratos.

\section{EFFECT OF SOURCE AND LEVEL OF FAT IN THE DIET OF WISTAR RATS (Rattus norvegicus) ON LIPOIDAL FRACTIONS IN THE SERUM}

\begin{abstract}
Four fat sources (soybean oil, canola oil, olive oil, swine fat) were evaluated with regard to their influence, at two levels in the diet (7 and 14\%), on some fat fractions in rats' blood. Thus, eight groups of Wistar rat (Rattus norvegicus) males were ad libitum fed eight different diets, containing the fat and level reported, for 56 days. The dosages of total serum cholesterol and thriacylglicerols were performed by the colorimetric/enzymatic method utilizing a commercial
\end{abstract}

specific kit. The HDL cholesterol was determined by precipitation of kilomicra (VLDL and LDL) by utilizing also a specific kit. The increase of fat in the diet to $14 \%$ raised the total cholesterol contents, serum HDL cholesterol and LDL + VLDL cholesterol when the source was swine fat. With $14 \%$ of fat in the diet, the lowest values of serum triacylglycerols were found for the fat sources soybean and canola oils, with values of 76.09 and $84.42 \mathrm{mg} / \mathrm{dl}$, respectively.

INDEX TERMS: Fat sources, blood analyses, cholesterol, thriacylglicerols, rats.

\section{INTRODUÇÃO}

A quantidade e a natureza da gordura ingerida diariamente influenciam a concentração do colesterol plasmático. Níveis elevados de colesterol no sangue estão relacionados com a incidência de doenças vasculares aterosclerótica, especialmente doenças coronarianas (Mahan \& Es-
cott-Stump, 1998; Champe \& Harvey, 2000). O "Food and Nutrition Board's Committee on Diet and Health", dos E.U. A, recomenda que o conteúdo de lipídios da dieta americana não deve exceder $30 \%$ do total calórico, os ácidos graxos saturados devem prover até $10 \%$ das calorias e o colesterol da dieta deve ser menos que $300 \mathrm{mg} / \mathrm{dia}$ (RDA, 1989).

1. Parte da dissertação de mestrado da primeira autora.

2. Mestre em Ciência dos Alimentos DCA/UFLA, Escola Agrotécnica Federal de Colatina, BR 259 KM 70, Caixa Postal 256 - 29709.910 - Colatina, ES. nil@intercol.com.br

3. Professores da UNIVERSIDADE FEDERAL DE LAVRAS/UFLA - Caixa Postal 37 - 37200-000 - Lavras, MG.

4. Mestre em Ciência dos Alimentos DCA/UFLA.

5. Graduanda em Agronomia/UFLA. 
Os principais processos envolvidos nas doenças cardíacas são ateroma, relacionado com efeito de longa duração, trombogênese, ligado a fatores dietéticos de curta duração, além de fatores que afetam o estilo de vida. Alta ingestão de gorduras saturadas, colesterol e calorias que conduz a obesidade são fatores que afetam o metabolismo lipídico (Assis, 1997).

Sendo a natureza e a quantidade de lipídios na dieta considerados fatores protetores e/ou promotores de problemas cardiovasculares, e considerando-se o elevado consumo de óleos vegetais frente ao de gordura animal, com o presente trabalho, objetivou-se verificar a influência do consumo de óleos de soja e canola, azeite de oliva e gordura suína em dois diferentes níveis sobre os teores de colesterol total, frações de HDL e VLDL+ LDL colesterol e triacilgliceróis no sangue de ratos machos da linhagem Wistar (Rattus norvegicus).

\section{MATERIAL E MÉTODOS}

\section{Local e material}

O experimento foi conduzido nos Departamentos de Ciência dos Alimentos e Medicina Veterinária da Universidade Federal de Lavras, Lavras, MG.

Foram utilizados 48 ratos Rattus norvegicus, machos da linhagem Wistar, com cerca de 40 dias de idade, provenientes do Departamento de Alimentos da Universidade Federal de Ouro Preto, MG. Após serem adaptados por três dias à dieta-padrão, no início da fase experimental, os animais estavam pesando entre 97 e 106 gramas. Foram divididos aleatoriamente em oito grupos de seis ratos cada um, colocados em gaiolas individuais, todos com livre acesso à água e à respectiva dieta (consumo ad libitum) em condições ambientais controladas, sob temperatura de $24^{\circ} \mathrm{C}$ a $28^{\circ} \mathrm{C}$ e períodos alternados de claro e escuro de 12 horas. A duração total do período experimental foi de 56 dias.

\section{Composição das dietas experimentais}

As dietas (Tabela 1) foram preparadas, segundo Reeves et al. (1993), do American Institute of Nutrition (AIN), com modificações na fonte e quantidades de gordura. As variações nos níveis de lipídios foram feitas em detrimento da fração glicídica.

A quantidade total de alimento necessária foi calculada e preparada previamente para o ensaio, sendo conservado em embalagens de polietileno, sob congelamento $\left(-14^{\circ} \mathrm{C}\right)$ até o dia anterior ao consumo, quando passavam para refrigeração $\left(5^{\circ} \mathrm{C}\right)$ e no início do dia de consumo, para temperatura ambiente.
Os ingredientes das dietas foram misturados em recipiente de plástico, peneirada três vezes e, posteriormente, os lipídios foram adicionados lenta e cuidadosamente. As dietas obtidas foram peneiradas por mais três vezes para obter produto bem homogeneizado.

As fontes lipídicas utilizadas, todas comerciais, foram: óleos de soja, canola, azeite de oliva e gordura suína. Os níveis de lipídios das dietas experimentais foram $7 \%$ e $14 \%$. A fração carboidrato da dieta foi fornecida por amido de milho comercial. Todos os componentes das dietas foram selecionados de acordo com os padrões da AIN-93 (Reeves et al., 1993).

\section{Sacrifício dos animais e coleta de amostras}

Ao final do experimento e após 16 horas de jejum, os animais foram anestesiados com éter etílico e o sangue, retirado dos grandes vasos abdominais. Em seguida, esse material foi centrifugado a $3000 \mathrm{rpm}$ por 5 minutos em centrífuga modelo-Eppendorf/Centrifuge 5415, para se obter o soro. Posteriormente, foram feitas as análises de colesterol total, HDL-colesterol e triacilgliceróis no soro sanguíneo.

\section{Determinação do colesterol total e triacilgli- ceróis séricos}

As dosagens de colesterol total e de triacilgliceróis no soro foram realizadas pelo método enzimático colorimétrico utilizando "kit" da In Vitro Diagnóstica Human. O colesterol foi determinado após a hidrólise enzimática e oxidação das amostras do soro. $\mathrm{O}$ indicador quinoneimina é formado a partir do peróxido de hidrogênio e 4aminofenazona na presença do fenol e peroxidase. Os triacilgliceróis foram determinados após hidrólise enzimática com lipases. $\mathrm{O}$ indicador é a quinoneimina formada a partir do peróxido de hidrogênio, 4-aminoantipirina e 4clorofenol sob a influência catalítica da peroxidase. Foi utilizado espectrofotômetro Varian CARY / 50 Prob uv visible, a $500 \mathrm{~nm}$ para as duas determinações.

\section{Determinação do HDL-colesterol sérico}

O colesterol em HDL (lipoproteína de alta densidade) foi determinado por precipitação dos quilomícrons, VLDL (lipoproteína de muita baixa densidade) e LDL (lipoproteína de baixa densidade) com ácido fosfotúngstico e cloreto de magnésio, e após a centrifugação a $4000 \mathrm{rpm}$, por 10 minutos, a fração HDL permanece no sobrenadante, sendo determinada utilizando-se "kit" e metodologia pelo método enzimático descrito anteriormente para o colesterol total. 
A fração LDL + VLDL colesterol foi determinada por diferença entre o colesterol total e o conteúdo em HDL, de acordo com a fórmula de Friedwald (Friedwald et al., 1972).

\section{Análises estatísticas}

$\mathrm{O}$ delineamento experimental utilizado foi o inteiramente casualizado em esquema fatorial $4 \times 2$, qua- tro fontes lipídicas (óleo de soja, canola, azeite de oliva e gordura suína) e dois níveis na dieta (7 e 14\%). Os resultados foram expressos na forma de médias e desvio padrão. Os dados foram analisados utilizando-se o pacote estatístico Sistema de Análise de Variância para Dados Balanceados - SISVAR, segundo Ferreira (2000). As médias dos tratamentos foram comparadas pelo teste de Tukey, ao nível de 5\% de significância.

TABELA 1 - Composição das dietas utilizadas durante o período experimental (56 dias) na alimentação de ratos machos linhagem Wistar (Rattus norvegicus).

\begin{tabular}{|c|c|c|c|c|c|c|c|c|}
\hline \multirow{2}{*}{$\begin{array}{c}\text { Ingredientes } \\
(\mathbf{g} / \mathbf{k g})\end{array}$} & \multicolumn{8}{|c|}{ Dietas* } \\
\hline & D1 & D2 & D3 & D4 & D5 & D6 & D7 & D8 \\
\hline Amido de milho** & 529,48 & 459,48 & 529,48 & 459,48 & 529,48 & 459,48 & 529,48 & 459,48 \\
\hline Caseína 86 \% proteína & 200,00 & 200,00 & 200,00 & 200,00 & 200,00 & 200,00 & 200,00 & 200,00 \\
\hline Sacarose & 100,00 & 100,00 & 100,00 & 100,00 & 100,00 & 100,00 & 100,00 & 100,00 \\
\hline Fibra (Celulose) & 50,00 & 50,00 & 50,00 & 50,00 & 50,00 & 50,00 & 50,00 & 50,00 \\
\hline Mistura Mineral & 35,00 & 35,00 & 35,00 & 35,00 & 35,00 & 35,00 & 35,00 & 35,00 \\
\hline Mistura Vitamínica & 10,00 & 10,00 & 10,00 & 10,00 & 10,00 & 10,00 & 10,00 & 10,00 \\
\hline L-Cistina & 3,00 & 3,00 & 3,00 & 3,00 & 3,00 & 3,00 & 3,00 & 3,00 \\
\hline Bitartarato de Colina & 2,50 & 2,50 & 2,50 & 2,50 & 2,50 & 2,50 & 2,50 & 2,50 \\
\hline $\mathrm{BHT} * * *$ & 0,014 & 0,014 & 0,014 & 0,014 & 0,014 & 0,014 & 0,014 & 0,014 \\
\hline Óleo de soja** & 70,00 & 140,00 & ----- & ----- & ----- & ----- & ----- & ----- \\
\hline Óleo de canola** & ---- & ---- & 70,00 & 140,00 & ---- & ---- & ----- & ----- \\
\hline Azeite de oliva** & ----- & ----- & ----- & ----- & 70,00 & 140,00 & ----- & ----- \\
\hline Gordura suína** & ---- & ----- & ----- & ----- & ----- & ----- & 70,00 & 140,00 \\
\hline Total & 1000,0 & 1000,0 & 1000,0 & 1000,0 & 1000,0 & 1000,0 & 1000,0 & 1000,0 \\
\hline
\end{tabular}

*Dietas experimentais: D1 - 7\% de óleo de soja; D2 - 14\% de óleo de soja; D3 - 7\% de óleo de canola; D4 $14 \%$ de óleo de canola; D5 - $7 \%$ de azeite de oliva; D6 -14 \% de azeite de oliva; D7 - $7 \%$ de gordura suína e D8 - $14 \%$ de gordura suína. A porcentagem de proteína de todas as dietas foi de 17,2 \%.

**Produto comercial adquirido no comércio local.

*** BHT (butil hidróxitolueno): antioxidante sintético.

Ciênc. agrotec., Lavras. V.27, n.5, p.1082-1088, set./out., 2003 


\section{RESULTADOS E DISCUSSÃO}

Para todas as variáveis analisadas no soro (colesterol total, HDL-colesterol, LDL+VLDL colesterol e triacilglicerol), houve interação significativa entre as fontes e níveis estudados, sendo realizado o desdobramento na análise estatística dos dados para a comparação de médias.

Na Tabela 2 encontram-se os teores médios de colesterol total do soro sanguíneo. Verifica-se que os teores de colesterol total no soro dos animais alimentados com $7 \%$ de óleo de soja ou azeite de oliva não apresentaram diferenças entre si $(\mathrm{P}>0,05)$. Esses teores foram superiores aos observados nos animais alimentados com óleo de canola ou gordura suína, e não foram diferentes entre si $(\mathrm{P}>0,05)$.

No caso do óleo de canola, foi demonstrado que o ácido oléico reduz os níveis de colesterol no sangue (Wankenne, 2001).

A gordura suína, embora possuindo $243 \mathrm{mg}$ de colesterol/100g (Franco, 2000), não contribuiu efetivamente na elevação do colesterol sérico, quando presente na dieta a $7 \%$.

Provavelmente a gordura suína, quando consumida em quantidade moderada, não interfere na elevação da taxa de colesterol sérico; entretanto, ao se aumentar o nível de gordura suína de 7 para 14\%, observou-se elevação da taxa do colesterol sérico. Esse fato pode ser conseqüência do excesso de ácidos graxos saturados, mais especificamente o ácido láurico, mirístico e palmítico, ditos como os três principais ácidos graxos causadores de hipercolesterolemia e promotores de aterosclerose (Champe \& Harvey, 2000). O ácido palmíti- co encontra-se presente na gordura suína em torno de $31 \%$, ao passo que, no óleo de soja, óleo de canola e azeite de oliva, os teores são $10 \%, 4 \%$ e $11 \%$, respectivamente (Griswold, 1972; Montgomery et al., 1994).

Nas dietas com $14 \%$ de lipídios, os maiores teores de colesterol foram observados nos animais que consumiram gordura suína $(82,55 \mathrm{mg} / \mathrm{dL})$, seguidos pelos alimentados com azeite de oliva, óleo de canola e, finalmente, com o menor valor de colesterol, os alimentados à base de óleo de soja $(57,93 \mathrm{mg} / \mathrm{dL})$. Consumindo óleo de canola em concentrações de 7 e 14\%, não foram observadas diferenças significativas no teor de colesterol total do soro dos animais e, no grupo alimentado com gordura suína, esse teor foi mais elevado ao se utilizar $14 \%$ dessa fonte lipídica.

No óleo de soja e azeite de oliva, observou-se uma redução significativa do colesterol quando o nível de lipídios da dieta passou de 7 para $14 \%$. Segundo Champe \& Harvey (2000), o nível de colesterol no plasma é moderadamente reduzido quando dietas pobres em colesterol são consumidas, sendo importante identificar e limitar os alimentos ricos em colesterol. $\mathrm{E}$, segundo os mesmos autores, as gorduras monoinsaturadas presentes no azeite de oliva são tão efetivas quanto as gorduras poliinsaturadas em reduzir o colesterol no sangue, quando substituem os ácidos graxos saturados.

Os teores de HDL-colesterol no soro dos animais alimentados com $7 \%$ de gordura suína ou óleo de soja não diferiram entre si, e foram menores $(\mathrm{P}<0,05)$ do que aqueles alimentados com óleo de canola e azeite de oliva. Esses teores não apresentaram diferenças entre si $(\mathrm{P}>0,05)$.

TABELA 2 - Valores médios (desvio padrão) de colesterol total do soro sanguíneo (mg/dL) de ratos machos da linhagem Wistar (Rattus norvegicus) alimentados por 56 dias com diferentes fontes lipídicas e dois níveis.

\begin{tabular}{lcc}
\hline \multirow{2}{*}{ Fontes lipídicas } & \multicolumn{2}{c}{ Colesterol total do soro sanguíneo (mg/dL) } \\
\cline { 2 - 3 } & Dieta com $\mathbf{7}$ \% de lipídios & Dieta com 14 \% de lipídios \\
\hline Óleo de soja & $73,10(1,86)$ a A & $57,93(1,40)$ d B \\
Óleo de canola & $66,98(1,95)$ b A & $65,58(1,78)$ c A \\
Azeite de oliva & $72,70(0,81)$ a A & $69,64(0,85)$ b B \\
Gordura suína & $63,56(1,43)$ b B & $82,55(1,89)$ a A
\end{tabular}

Médias seguidas de letras diferentes, minúsculas, nas colunas são diferentes $(P \leq 0,05)$ pelo teste de Tukey e maiúsculas, nas linhas, pelo teste $\mathbf{F}$. 
TABELA 3 - Médias (desvio padrão) de HDL-colesterol do soro (mg/dL) de ratos machos da linhagem Wistar (Rattus norvegicus) alimentados por 56 dias com diferentes fontes lipídicas e dois níveis.

\begin{tabular}{lcc}
\hline \multirow{2}{*}{ Fontes lipídicas } & \multicolumn{2}{c}{ HDL-colesterol do soro (mg/dL) } \\
\cline { 2 - 3 } & Dieta com 7\% de lipídios & Dieta com 14\% de lipídios \\
\hline Óleo de soja & $36,24(1,27)$ b B & $42,56(0,90)$ b A \\
Óleo de canola & $40,04(1,44)$ a B & $42,02(1,60)$ b A \\
Azeite de oliva & $40,69(1,01)$ a B & $43,19(1,69)$ b A \\
Gordura suína & $35,89(1,49)$ b B & $47,07(1,61)$ a A \\
\hline
\end{tabular}

Médias seguidas de letras diferentes, minúsculas, nas colunas são diferentes $(P \leq \mathbf{0 , 0 5})$ pelo teste de Tukey e maiúsculas, nas linhas, pelo teste $\mathrm{F}$.

Conforme Champe e Harvey (2000), os ácidos graxos monoinsaturados ácido oléico, ao contrário dos poliinsaturados ômega 6 (ácido linoléico), quando consumidos, não reduzem os níveis de HDL-colesterol no sangue. Assim, os grupos de animais que consumiram azeite de oliva e óleo de canola, ricos em ácidos graxos monoinsaturados, foram os grupos que tiveram maiores valores de HDL-colesterol.

Os animais que consumiram $14 \%$ de gordura suína tiveram o maior teor de HDL-colesterol e superior às demais fontes $(\mathrm{P}<0,05)$. Nesse nível, os teores de HDL-colesterol dos animais alimentados com óleo de soja, canola e azeite de oliva não apresentaram diferenças entre si.

Ao se comparar os teores de HDL-colesterol dos animais alimentados com 7 e 14\% de lipídios na dieta, verificou-se que em todas as fontes utilizadas ocorreu aumento dessa lipoproteína com a elevação no percentual de lipídio na dieta. No caso do azeite de oliva e gordura suína, esse fato deve estar relacionado com a presença de ácidos graxos monoinsaturados (ácido oléico) nessas fontes. Segundo Mahan \& Escott-Stump (1998), os efeitos dos ácidos graxos monoinsaturados sobre HDL-colesterol dependem do conteúdo total de gordura da dieta. À medida que aumenta o nível de lipídios e ácidos graxos monoinsaturados da dieta, o HDL-colesterol aumenta levemente, comparando a uma dieta com menor nível lipídico.

$\mathrm{Na}$ Tabela 4, apresentam-se os teores de LDL+VLDL-colesterol no soro. Com 7\% de lipídios na dieta, o teor de LDL+VLDL-colesterol do soro dos animais alimentados com óleo de soja foi maior do que os demais. Os menores teores foram observados nos grupos de animais alimentados com óleo de canola ou gordura suína que não diferiram entre si $(\mathrm{P}>0,05)$.

Ao nível de $14 \%$ de lipídios na dieta, o maior teor de LDL+VLDL-colesterol foi observado nos animais que consumiram gordura suína, seguida em ordem decrescente por aqueles que consumiram azeite de oliva, óleo de canola e óleo de soja.

Quando aumentou de 7 para $14 \%$ a quantidade de lipídios na dieta, houve, também, um acréscimo no nível de LDL+VLDL-colesterol quando a fonte lipídica foi a gordura suína e um decréscimo nas demais fontes utilizadas. Esse acréscimo se deve provavelmente à presença de alguns ácidos graxos saturados capazes de induzir a síntese hepática de VLDL e inibir a captação das partículas resultantes do metabolismo de VLDL, como as IDL, que são catabolizadas no fígado, via receptores específicos (Keys et al., 1965; Green et al., 1984, citados por Sousa, 1996).

A redução da LDL+VLDL-colesterol no soro dos animais utilizando óleo de soja ao elevar o nível de 7 para $14 \%$ na dieta relaciona-se com os valores de triacilglicerol e colesterol total observados nesta fonte lipídica. Como se pode observar, o aumento do nível de lipídios na dieta causou uma redução no colesterol total do soro dos animais alimentados com o óleo de soja. Como a VLDL-colesterol é composta de $60 \%$ de triacilglicerol e $20 \%$ de colesterol e ésteres de colesteril e a LDL-colesterol contém $8 \%$ de triacilglicerol e $50 \%$ de colesterol e ésteres de colesteril (Champe \& Harvey, 2000), a redução da LDL+VLDL-colesterol pode estar relacionada à redução de colesterol total do soro, ao alimentar os ratos com óleo de soja. 
Ao utilizar o nível lipídico de 7\%, o maior valor de triacilglicerol sérico (Tabela 5) foi observado nos animais que consumiram a dieta à base de óleo de soja, seguido pelos animais que consumiram dieta à base de gordura suína e óleo de canola, os quais não apresentaram diferenças entre si, e os menores valores nesse nível foram observados nos animais alimentados com azeite de oliva $(\mathrm{P}<0,05)$.

Para as fontes lipídicas estudadas, óleo de soja e canola, observa-se que ocorreu uma redução dos níveis de triacilglicerol no soro dos animais com o aumento de 7 para $14 \%$ de inclusão desses óleos na dieta, devido, possivelmente, ao aumento dos níveis de ácido linoléico e alfa-linolênico na dieta. Segundo Neves (1997), o ácido linoléico reduz os níveis de triacilgliceróis séricos. Também foi demonstrado que $\mathrm{o}$ acido alfa- linolênico tem um efeito eficaz na redução dos triacilgliceróis do sangue, assim como na redução no agrupamento de plaquetas e aumento no tempo de coagulação (Wankenne, 2001).

Jong (1996), quando aumentou a concentração de 7 para $30 \%$ de lipídios na dieta, também observou redução nos níveis de triacilgliceróis de 156 para 104 $\mathrm{mg} / \mathrm{dL}$, e elevação de 86 para $155 \mathrm{mg} / \mathrm{dL}$ dos triacilgliceróis, quando a fonte era gordura de coco.

Herman et al. (1991) informaram que quando se comparam gorduras saturadas com insaturadas, ricas em ácido linoléico presentes em plantas ricas nesse ácido graxo, foi verificada redução de triacilgliceróis com o consumo desse ácido graxo. Também o ácido linolênico promove redução de triacilgliceróis plasmáticos (Pimentel \& Caruso, 1999; Champe \& Harvey, 2000).

TABELA 4 - Médias (desvio padrão) de LDL+VLDL colesterol do soro (mg/dL) de ratos machos da linhagem Wistar (Rattus norvegicus) alimentados por 56 dias com diferentes fontes lipídicas e dois níveis.

\begin{tabular}{lcc}
\hline \multirow{2}{*}{ Fontes lipídicas } & \multicolumn{2}{c}{ LDL+VLDL colesterol (mg/dL) } \\
\cline { 2 - 3 } & Dieta com 7\% de lipídios & Dieta com 14\% de lipídios \\
\hline Óleo de soja & $36,85(1,19)$ a A & $15,37(0,54) \mathrm{d}$ B \\
Óleo de canola & $26,94(0,61)$ c A & $23,57(1,20)$ c B \\
Azeite de oliva & $32,02(1,01)$ b A & $26,46(1,48)$ b B \\
Gordura suína & $27,67(0,49)$ c B & $35,48(1,26)$ a A \\
\hline
\end{tabular}

Médias seguidas de letras diferentes, minúsculas, nas colunas são diferentes $(P \leq 0,05)$ pelo teste de Tukey e maiúsculas, nas linhas, pelo teste $\mathrm{F}$.

TABELA 5 - Médias (desvio padrão) de triacilglicerol do soro (mg/dL) de ratos machos da linhagem Wistar (Rattus norvegicus) alimentados por 56 dias com diferentes fontes lipídicas e dois níveis.

\begin{tabular}{lcc}
\hline \multirow{2}{*}{ Fontes lipídicas } & \multicolumn{2}{c}{ Triacilglicerol do soro $(\mathbf{m g} / \mathbf{d L})$} \\
\cline { 2 - 3 } & Dieta com 7\% de lipídios & Dieta com 14\% de lipídios \\
\hline Óleo de soja & $155,48(2,47)$ a A & $76,09(2,58)$ c B \\
Óleo de canola & $131,82(2,30)$ b A & $84,42(7,95)$ c B \\
Azeite de oliva & $110,70(9,88)$ c A & $109,34(8,87)$ b A \\
Gordura suína & $133,19(1,63)$ b A & $137,39(4,06)$ a A \\
\hline
\end{tabular}

Médias seguidas de letras diferentes, minúsculas, nas colunas são diferentes $(P \leq 0,05)$ pelo teste de Tukey e maiúsculas, nas linhas, pelo teste $\mathbf{F}$. 
Nos grupos de animais que consumiram dietas à base de azeite de oliva e gordura suína, não foram observadas diferenças no triacilglicerol do soro entre os níveis 7 e 14\% de inclusão na dieta, provavelmente devido ao maior percentual de ácido monoinsaturado presente nessas fontes lipídicas, pois, segundo Assis (1997), os ácidos graxos monoinsaturados parecem não interferir sobre os níveis de triacilgliceróis séricos.

\section{CONCLUSÕES}

O aumento do nível de 7 para 14\% de lipídios na dieta elevou o colesterol total sérico, quando a fonte foi a gordura suína, e reduziu com o óleo de soja e azeite de oliva.

A gordura suína, quando consumida em nível de $7 \%$ na dieta, não elevou os níveis de colesterol sérico. Em excesso, com 14\%, resultou em elevada quantidade de LDL+VLDL colesterol no soro, embora o HDL colesterol tenha sido também elevado.

$\mathrm{O}$ consumo de dieta à base de azeite de oliva a $7 \%$ foi o que apresentou maior redução do triacilglicerol sérico entre as fontes lipídicas estudadas. Aumentando o nível lipídico da dieta para $14 \%$, os menores valores de triacilgliceróis foram observados quando a fonte lipídica foi o óleo de soja e o de canola.

\section{REFERÊNCIAS BIBLIOGRÁFICAS}

ASSIS, M.A.A. Consulta de nutrição: controle e prevenção do colesterol elevado. Florianópolis: Insular, 1997. 166 p.

CHAMPE, P. C.; HARVEY, R. A. Bioquímica ilustrada. 2. ed. Porto Alegre: Artmed, 2000. 446 p.

FERREIRA, D. F. Análises estatísticas por meio do Sisvar para Windows: versão 4.0. In: REUNIÃO ANUAL DA REGIÃO BRASILEIRA DA SOCIEDADE INTERNACIONAL DE BIOMETRIA, 45., 2000, São Carlos. Anais... São Carlos: SIB, 2000. p. 255-258.

FRANCO, G. Tabela de composição química dos alimentos. 9. ed. São Paulo: Atheneu, 2000. 307 p.

FRIEDWALD, W. T.; LEVY, R. I.; FREDRICKSON, D. S. Estimation of the concentration of low density lipoprotein cholesterol in plasma, without use of preparative ultracentrifuge. Clinical chemistry, Baltimore, v. 18, p. 499-502, 1972.
GRISWOLD, R. M. Estudo experimental dos alimentos. São Paulo: Edgard Blucher, 1972. 469 p.

HERMAN, S.; SEDIAOETAMA, A. D.; KARYADI, D.; BEYNEN, A. C. Influence of background composition of the diet on the lipemic effect of fish oil vs. corn oil in rats. The Journal of Nutrition, Bethesda, v. 121, n. 5, p. 622-630, May 1991.

JONG, E. V. Influência de dietas morno e hiperlipídicas sobre o perfil nutricional, parâmetros bioquímicos séricos e estruturais do fígado de ratos Wistar. 1996. 140 f. Tese (Doutorado em Ciência da Nutrição) - Universidade Estadual de Campinas, Campinas, 1996.

MAHAN, L. K.; ESCOTT-STUMP, S. Alimentos, nutrição e dietoterapia. 9. ed. São Paulo: Roca, 1998. 1179 p.

MONTGOMERY, R.; CONWAY, T. W.; SPECTOR, A. A. Bioquímica: uma abordagem dirigida por casos. 5. ed. São Paulo: Artes Médicas, 1994. 477 p.

NEVES, N. M. S. Nutrição e doença cardiovascular. Rio de Janeiro: Guanabara Koogan, 1997. 109 p.

PIMENTEL, S. A.; CARUSO, M. S. F. Ácido gamalinolênico: fontes e perspectivas de sua aplicação terapêutica. Boletim SBCTA, Campinas, v. 33, n. 2, p. 162-167, jul./dez. 1999.

RECOMMENDED DIETARY ALLOWANCES. Subcommittee on the Tenht Edition of the RDAs. Food and Nutritional Board. Commission of Life Sciences. National Research Council. 10. ed. Washington, 1989. 283 p.

REEVES, P. G.; NIELSEN, F. H.; FAHEY JUNIOR, G. C. AIN-93 purified diets for laboratory rodents: final report of the American Institute of Nutrition Ad Hoc writing committe on the reformulation of the AIN-76A rodent diet. The Journal of Nutrition, Bethesda, v. 123, n. 11, p. 1939-1951, Nov. 1993.

SOUSA, R. V. Óleo de tambaqui (Colossoma macropomum, Cuvier): características nutricionais e ação no metabolismo de lipídios em ratos hipercolesterolêmicos. 1996. 62 f. Dissertação (Mestrado em BioquímicaImunologia) - Universidade Federal de Minas Gerais, Belo Horizonte, 1996.

WANKENNE, M. A. (Ed.). Canola: OGM or not! Aditivos \& Ingredientes, São Paulo, n. 17, p. 28-36, nov./dez. 2001. 